\title{
As crianças e o brincar no contexto escolar: tempos (in)sensíveis
}

\author{
Andrize Ramires Costa $a^{a, b} \mathbb{1} *$
}

Palavras Chave:

Brincar;

Tempo;

Racionalidade;

Educação Infantil.

\begin{abstract}
RESUMO
Neste artigo, em formato de ensaio, buscamos a reflexão demarcada por uma dicotomia na Educação Infantil em que, de um lado temos o tempo cronometrado, medido, regulado pela opressão dos relógios dos adultos, concebido pela objetividade dos números, horários e rotinas, representante do mundo pensado, racionalizado. De outro, temos o tempo sentido, percebido pelas crianças, a subjetividade, a experiência e o acontecimento, representantes do mundo vivido. Concluimos que, não obstante a feição social do tempo, pode possibilitar as crianças expandir suas capacidades criativas e inventivas pelo brincar e ser uma aposta ético-política para enfrentar a instrumentalização do tempo e seu domínio na experiência escolar.
\end{abstract}

\section{Keywords:}

Playing;

Time;

Rationality;

Child Education.

Palavras Chave:

Jugar;

Tiempo;

Racionalidad;

Educación Infantil.

\begin{abstract}
In this paper, in an essay format, we pursue the reflection delimited by a dichotomy in Early Childhood Education where, on the one hand, time is tracked, measured, regulated by the oppression of clocks of adults, conceived by the objectivity of numbers, schedules and routines, representative of the thought and rationalized world. On the other hand, we have the time felt and perceived by the children, the subjectivity, the experience and the fact, representatives of the lived world. We conclude that, despite the social aspect of time, allowing children to broaden their creative and inventive capacities by playing is an ethical-political attempt to face the instrumentalization of time and its power in the school experience.
\end{abstract}

\section{RESUMEN}

En este artículo, en formato de ensayo, buscamos la reflexión demarcada por una dicotomía en la Educación Infantil donde, por un lado tenemos el tiempo cronometrado, medido, regulado por la opresión de los relojes de los adultos, concebido por la objetividad de los números, horarios y rutinas, el mundo pensado, racionalizado. De otro, tenemos el tiempo sentido, percibido por los niños, la subjetividad, la experiencia y el acontecimiento, representantes del mundo vivido. Concluimos que, a pesar de la aparición social del tiempo, puede permitir a los niños expandir sus capacidades creativas e inventivas por el juego y ser una apuesta ético-política para enfrentar la instrumentalización del tiempo y su dominio en la experiencia escolar

\footnotetext{
${ }^{a}$ Universidade Federal de Santa Catarina, Florianópolis, SC, Brasil.

b Universidade Federal de Pelotas - Escola Superior de Educação Física - Programa de Pós-Graduação em Educação Física - Pelotas, Rio Grande do Sul, Brasil.
}

\section{*Autor correspondente: \\ Andrize Ramires Costa \\ E-mail: andrize.costa@gmail.com}




\section{INTRODUÇÃO}

Os relógios são máquinas de medir o tempo como uma quantidade homogênea, divisível e equivalente. O tempo do relógio é um tempo igual a si mesmo, divisível em unidades menores e equivalentes em qualquer ponto de experiência, em qualquer espaço e em qualquer contexto. Os relógios transformam a duração num percurso abstrato no espaço, embora o movimento dos ponteiros mantenha ainda uma relação física entre percepção visual e medida de tempo.

Conforme Melucci (2004), as experiências de tempo dos sujeitos, nunca ou raramente, coincidem com aquilo que o relógio decreta. A relação linear de tempo, não é nada simples porque concomitante a ela vivemos ainda outros entrelaçamentos entre as dimensões do tempo. Nas sabedorias das culturas passadas, cita 0 autor, existe uma figura que procura sintetizar essas experiências contraditórias que é a representação espiral do tempo.

Durante as brincadeiras das crianças nas escolas algo vem nos instigando. Como as crianças vêm ocupando seu tempo? Faz sentido para a criança ter hora certa para brincar? Por que razão os adultos determinam o momento apropriado para ir ao pátio ou ao parque para brincar? Esses questionamentos nos inquietam e configuram uma dicotomia entre o tempo regulado, cronometrado, coercitivo, medido quantitativamente pelos relógios dos adultos e o tempo sentido e percebido com fruição ou muita intensidade por parte das crianças.

O conceito de tempo surge dos gregos antigos que convocaram os mitos para dar um entendimento ao tempo. Para tal, forjaram três conceitos: Chronos, Kairós e Aeon. O Chronos é o tempo cronológico, sequencial e linear que pode ser medido. Surge no princípio dos tempos formado por si mesmo designando a continuidade do tempo sucessivo; é a soma do passado, presente e futuro. Kairós refere-se a um momento indeterminado em que algo especial acontece: um tempo existencial, no qual os gregos acreditavam para enfrentar o cruel e tirano Chronos. Kairós significa medida, proporção, momento crítico, temporada, oportunidade. Aeon é um tempo sagrado e eterno sem uma medida precisa, um tempo da criatividade onde as horas não passam matematicamente: é a intensidade do tempo da vida humana, um destino, uma duração, uma temporalidade não numerável nem sucessiva, mas intensiva. Enquanto Chronos é de natureza quantitativa, Kairós e Aeon possuem uma natureza qualitativa. (Francesch, 2011)

Uma das representações de Chronos é a de um homem que devora o seu próprio filho, num ato de canibalismo não muito difícil de compreender na atualidade. Esta representação tenta mostrar que fugir desse tempo tirano é impossível e que todos seriam mais cedo ou mais tarde vencidos ou devorados por ele e atualizados.

Assim como para os gregos antigos, na atualidade parece existir uma polarização em relação à experiência humana no que diz respeito ao tempo: uma compreensão de tempo é matematicamente concebida pelo mundo da racionalidade instrumental que convive ao lado de outra forjada no tempo vivido e nos auxilia a compreender que o brincar da criança pode ser concebido e tratado em duas perspectivas diferentes de tempo na qual aprofundaremos neste ensaio teórico.

A partir da modernidade, sobretudo com os efeitos da revolução industrial e científica, a experiência do brincar como acontecimento, cada vez mais rara, genuína e legítima, como aquilo "que nos passa, o que nos acontece, o que nos toca" (Bondía, 2002, p. 21), em relação ao tempo se bipolariza e brincar passa a ser vivenciado e percebido de modo diferente entre crianças e adultos, pois são dois tempos em oposição: o tempo de brincar da criança está próximo de Kairos ou Aeon, enquanto para os adultos que controlam o tempo das crianças e atuam orientados por uma concepção de tempo cronológico, o concebem como o Chronos que a todos oprime e enquadra.

Isso se deve ao relatado anteriormente, o mundo racionalizado e o mundo experienciado foi dividido nas ciências modernas ${ }^{1}$ resultando, de um lado, no tempo concebido pela exterioridade, na objetividade e nos números, um tempo prescrito, controlado e representante do mundo pensado (racionalizado); e de outro, o mundo da interioridade, substantivado e espiritualizado na subjetividade, na experiência vivida, representante do mundo vivido (experienciado).

Para a criança, o tempo é sentido como uma duração em relação à experiência como acontecimento. A percepção de tempo pode ser mais alargada e intensa e não permite à criança que ela tenha préocupação com relação aos instrumentos de medição do tempo mais usuais, como o relógio e o calendário. Então essa percepção da criança sobre o tempo nos acontecimentos é completamente diferente a dos adultos, sobretudo porque ela brinca em total atenção ao que faz no presente (Maturana e Verden-Zöller, 2004).

1 Esta 'divisão' deve também ser creditada a configuração do capitalismo e do liberalismo como sistemas econômicos e politicos da modernidade, segundo Elias (1998), as características deste capitalismo tem necessidades e exigências econômicas e políticas em relação ao tempo, especialmente ao controle do tempo. 
Já os adultos têm outra relação com o tempo, regulam as atividades e as agendas por instrumentos utilizados para controlar uma vida cheia de compromissos e tratam o brincar das crianças de modo pré-determinado pelo tempo do relógio, linearmente, como se brincar fosse uma sucessão de fatos marcantes com início e fim. A fantasia e a imaginação são postas em segundo plano, em virtude de uma cultura que pressiona pais e professores a reduzir o tempo de brincar sob o pretexto de prepará-las para a vida adulta, esquecendo-se do modo como as crianças aprendem é genuinamente brincando. Colocar as crianças em "fast forward" 2 é arriscar fazê-las perder seu desejo natural de aprender e aumentar o risco delas se tornarem ansiosas, deprimidas e infelizes. "A infância consiste essencialmente em se fazer descobertas. É um período em que as crianças aprendem sobre si mesmas e sobre suas próprias capacidades. E essas descobertas não ocorrem no contexto de aulas estruturadas" (HirshPasek et al., 2006, p. 12).

\section{A CRIANÇA SEM TEMPO PARA BRINCAR}

O tempo sempre foi uma dimensão controladora da vida escolar. Sua estrutura estabelecida por um somatório de critérios curriculares define a vigência do cenário cotidiano da troca e aquisição de saberes. Faz parte de uma configuração histórica, social e cultural da escola através de inúmeros dispositivos: calendário e jornada escolar, rotinas escolares, horários, currículo, unidades de ensino, ciclos, datas comemorativas, conteúdos programáticos e regulação das relações sociais e pessoais. É multidimensional, tem uma identidade própria decorrente da construção simbólica da escola.

As instituições, ao determinar um único tempo escolar para todos os alunos, acabam por produzir sujeitos 'atrasados', ou seja, aqueles que não acompanham o tempo e ritmo instituído pelos currículos. Conforme Silva (2011) escalonar desse modo o tempo de escolarização tem duas consequências fundamentais: por um lado, faz com que o fracasso ou atraso escolar apareçam como fatos naturais; e por outro, desempenham o papel de posicionar os alunos em uma pirâmide escolar. Sob a égide do cientificismo característico da Modernidade o racionalismo imperou na elaboração dos currículos, consolidando a rigidez na organização do tempo linear escolar que os professores assumiram como modelo da normal.

2 Termo utilizado pelo Prof. Dr. Manuel Sarmento, em Educação Infantil em Jornada de tempo integral: dilemas e perspectivas (2015) e que remete a um avanço rápido provocado pela tensão da escolarização precoce.
Silva (2011) ainda enfatiza que a escola é uma invenção cultural singular caracterizada por sua aparência física reconhecível, uma forma de utilizar o espaço e o tempo, um modo de desenvolver a atividade dos alunos. A escola é um meio institucional regulado pelos adultos que, em princípio, não foi pensada para satisfazer as necessidades das crianças. Suas carteiras, seus horários, a sucessão de graus e níveis, os conteúdos dos currículos, as provas, seus professores especializados foram organizados, tendo, em vista, a formação futura dos alunos.

$\mathrm{Na}$ escola, o tempo medido e o tempo vivido também têm as suas manifestações. A escola contemporânea, perante as pressões econômicas e produtivas, elevou a ideia do aluno como ofício. A escola de hoje forja uma identidade da criança projetada através do seu desempenho, acima de tudo, pela competência, aprovação e sucesso. $O$ ofício de aluno é a socialização com valorização da competitividade e da autonomia (compulsiva), o que tem o preço do constrangimento do mundo de coisas e valores da criança que dão lugar ao trabalho escolar para se promover os resultados da aprendizagem, através dos programas educativos que restringem o espaço-tempo da criança, colocando-a sob um controle mais prolongado dos adultos.

Este é um fator contextual que pode afetar a capacidade da criança para se envolver e desenvolver a dimensão lúdica, favorável ao universo do brincar e jogar nas rotinas da Educação da Infância. O sentido de organização racional do tempo, na escola, vai priorizar a repetição de exercícios com o intuito de aprender a aprender, conforme as regras impostas pelos adultos. Estas regras correspondem à organização do cotidiano na forma da ordem do tempo, "adquirida tanto pela ordem em que ocorrem como pelas constantes orientações que são expressas pelas educadoras. 0 problema aqui está no fato evidenciado: as crianças não se importam se a hora e o local (para brincar) são adequados" (Barreto, 2013, p. 204).

Desta maneira, as rotinas podem ser massacrantes e estafantes, inibidoras da liberdade criativa. Atualmente, as crianças têm um tempo muito maior de escolarização, tendo sido aumentados os dias letivos e diminuído as férias, o que se deve, em parte, à própria história da infância e ao desenvolvimento das sociedades industriais e urbanas, pois, na medida em que as mulheres passam a ocupar mais intensamente os postos de trabalho, as famílias modificam as suas rotinas e os filhos passam a ser assistidos pelas escolas por um tempo maior. A escola, como elemento do processo civilizador urbano, adota medidas reguladoras e disciplinadoras das crianças. Como resultado, temos, assim, uma prática educativa que 
configura dicotomicamente o tempo escolar em várias dimensões: o tempo prescrito e o tempo vivido; o tempo a ser seguido e o tempo a ser burlado; o tempo livre e o tempo controlado; um tempo medido e um tempo subjetivo (Fernandes, 2008).

Frequentemente, o tempo para brincar é determinado na escola, podendo estar administrado entre outros momentos destinados a rotina escolar (Barbosa, 2006). Além disso, o tempo destinado ao brincar está situado entre esses momentos que devem ser cansativos e estafantes e, portanto, o tempo do recreio serve para recuperar as forças e a energia que esgota o corpo da criança durante as aulas.

Assim, o recreio não serve para brincar, mas para descansar, restaurar, restabelecer e revitalizar; não vale por si mesmo, enquanto hora destinada e apropriada para brincar, mas serve para outro tempo, o do trabalho escolar e demandas da cultura escolar. Deste modo, o brincar na escola parece encontrar-se sempre num tempo que não é para ser vivido plenamente porque está sempre ao serviço de algo que é mais importante: produzir, restabelecer, revigorar, recuperar. $O$ uso racional, controlado e rígido do tempo na escola repercute em uma concepção de infância, de criança e da própria escola enquanto um lugar ou sistema meramente produtivo que não parece comportar outras temporalidades, outros ritmos, mais alongados e consoantes com as horas absorventes. (Fernandes e Mignot, 2008)

Ainda temos observado um processo de apressamento da infância. Desde muito cedo pais e professores potencializam o tempo de modo a promover uma "criança organizada" tendo todos os minutos programados, o que tem produzido crianças estressadas, deprimidas, fóbicas, ansiosas, esmagadas por mudanças sociais desnorteadoras que depositam cada vez mais expectativas no futuro delas, em detrimento do seu presente. Criam-se expectativas em relação à antecipação das capacidades das crianças e a necessidade de estimulá-las a alcançar cada vez mais cedo a aquisição de determinadas habilidades, principalmente cognitivas e motoras. "Na atualidade as crianças dispõem de agendas superlotadas, séries inflacionadas e a alfabetização têm sido antecipada para o período entre os zero e seis anos" (Hirsh-Pasek et al. 2006, p. 64).

Costa (2015) destaca que a lentidão muitas vezes é tratada como doença e para que não caiam na lentidão das atividades e "desperdício" de tempo com o brincar sem objetivos pré-determinados, muitas crianças são conduzidas pelos adultos em múltiplas atividades paralelas à creche ou cscola, como balé, música, esportes, estudo de línguas, informática entre outras atividades que buscam potencializar o "tempo" das crianças com as chamadas atividades formais da creche ou escola.

\section{O TEMPO DOS RELÓGIOS E A SUA RELAÇÃO COM O BRINCAR}

A mensuração do tempo surge a partir da era moderna, num movimento complexo que autorregula e sensibiliza o homem em relação ao tempo, através de instrumentos que passam a exercer uma pressão que se presta eminentemente para suscitar o desenvolvimento de uma autodisciplina nos indivíduos, sob uma pressão relativamente discreta, comedida, uniforme e aparentemente desprovida de violência, mas que nem por isso é menos onipresente e da qual é impossível escapar (Elias, 1998).

Do surgimento dos relógios como meio de orientação até a generalização do seu uso, surge um questionamento que tem se refletido com base no estilo de vida das pessoas em nossa sociedade: 0 tempo está tão enraizado na nossa consciência, que parece materializar-se a ponto de ser possível tocálo, temos a impressão que o tempo passa, quando na verdade o que nos acontece é o transcorrer das nossas vidas.

Assim, os professores compreendem certa necessidade de organização, disciplinarização e regulação do tempo para que possam coexistir na escola (e há quem afirme a necessidade da sua administração rigorosa como meio disciplinador de hábitos), com o intuito de educar as crianças pequenas a compartilhar espaços harmoniosamente. O problema está exatamente no uso implacável do relógio como uma espécie de tirano a quem se deve obediência incondicional, como se todas as ações e modos de sentir, pensar e agir pudessem ser cronometrados. Este é mais um modo de controlar e ajustar a criança ao mundo do adulto seja através da restrição do tempo de brincar ou pela supressão da liberdade para tal.

A brincadeira é uma atitude fundamental e facilmente perdível, pois requer total inocência, chamamos de brincadeira qualquer atividade humana praticada numa relação lúdica, isto é, qualquer atividade realizada no presente e com atenção voltada para ela própria e não para seus resultados (Maturana e Verden-Zöller, 2004, p. 231).

Refletindo sobre o tempo Chronos em oposição ao tempo vivdo pela criança, o tema perpassa um profundo paradoxo que a própria crítica exige: duas posições opostas em torno do tempo articuladas com o fenômeno do brincar. Assim, perguntamos: o que ou quem determina a duração do brincar? É o tempo 
determinado pelo tempo dos adultos e das instituições? É o sentimento de duração da criança com relação aos acontecimentos? É a percepção que a criança tem em relação à brincadeira? Enfim, é o tempo objetivo ou o subjetivo que regula a brincadeira?

Sabemos que não é possível responder a todos esses questionamentos, no entanto, situar a ação de brincar em relação ao elemento que mais o restringe e o aprisiona, pode ajudar a compreender sobre como temos lidado com essa questão na escola e, de modo mais aproximado, como as crianças produzem e promovem suas experiências e porque é importante brincar e se movimentar em liberdade, sem constrangimentos e delimitação incondicional do tempo por parte dos professores ou das exigências da ordem da produtividade.

$O$ excesso de informação nas crianças com a maior velocidade possível tem valor tão nutritivo quanto ingerir um sanduíche. Muito melhor é estudar num ritmo tranquilo, procurando explorar com mais profundidade os temas, estabelecer conexões, aprender a pensar e não apenas a passar nos exames. [...] aprender devagar pode abrir horizontes e revigorar a mente. Se não educássemos as crianças a ficar obcecadas com a velocidade, com provas, metas e prazos, as crianças teriam liberdade de se apaixonar pelo aprendizado (Honoré 2005).

Devemos oportunizar ritmos mais suaves com as crianças bem como a exploração do mundo da arte, promovendo a expressão, a comunicação, as linguagens e, sobretudo, o diálogo que a criança necessita para inserir-se enquanto sujeito que quer e sabe como conversar com o mundo através da imaginação e da fantasia.

Mas muitas vezes vamos à contramão, sequestramos o tempo subjetivo das crianças quando as impomos a pressão do tempo Chronos, sequetramos possibilidades de relações interpessoais significativas, de conhecer o meio e a natureza ao seu redor e de fortalecer uma relação ecológica com o território, resultando na ausência de consciência com relação a biodiversidade e uma visão desintegrada entre passado [história e memória] presente [intensidade e responsabilidade] e futuro [como perseverança consequente de nossa responsabilidade no momento atual, através da projeção de ações refletidas e articuladas com calma] (Francesch, 2011).

\section{DEVOLVER O DIREITO AO TEMPO DE BRINCAR}

A experiência do brincar cruza diferentes tempos e lugares, passados, presentes e futuros, sendo marcada ao mesmo tempo pela continuidade e pela mudança. Pelo fato de se situar em um contexto histórico e social, as crianças sentem-se irresistivelmente atraídas pelo resíduo que surge na construção, no trabalho de jardinagem ou doméstico, na costura ou na marcenaria. Mas essa experiência não é simplesmente reproduzida, e sim recriada a partir do que a criança traz de novo, com o seu poder de imaginar, criar, reinventar e produzir cultura (Benjamin, 1984).

Enquanto brinca, a criança procura desesperadamente sobreviver e, para isso, quer apenas o auxílio dos adultos. Ou seja, "Brincar não tem nada a ver com o futuro. Não é uma preparação para nada, é fazer o que se faz em total aceitação, sem considerações que neguem a sua legitimidade Para aprender a brincar, devemos entrar numa situação na qual não podemos senão atentar para o presente" (Maturana e Verden-Zöller, 2004).

Ao observarmos as crianças brincando, podemos conhecê-los melhor, pois uma parte de seus mundos e experiências revela-se nas ações e significados que constroem nas suas brincadeiras. Isso porque o processo do brincar referencia-se naquilo que os sujeitos conhecem e vivenciam. Com base em suas experiências, os sujeitos reelaboram e reinterpretam situações de sua vida cotidiana e as referências de seus contextos.

A brincadeira não é algo já dado na vida do ser humano, ou seja, aprende-se a brincar, desde cedo, nas relações que os sujeitos estabelecem com os outros e com a cultura. Quando as crianças pequenas brincam de ser "outros" (pai, mãe, médico, monstro, fada, bruxa, ladrão, polícia etc.), refletem sobre suas relações com esses outros e tomam consciência de si e do mundo, estabelecendo outras lógicas e fronteiras de significação da vida (Borba, 2016). O brincar envolve, portanto, complexos processos de articulação entre o já dado e o novo, entre a experiência, a imaginação, a realidade, fantasia, mas para isso é preciso que se tenha tempo como já aprofundamos em nossas reflexões.

Borba (2018) afirma que brincar com o outro, é uma experiência de cultura e um complexo processo interativo e reflexivo que envolve a construção de habilidades, conhecimentos e valores sobre o mundo. O brincar contém o mundo e ao mesmo tempo contribui para expressá-lo, pensá-lo e recriá-lo. Dessa forma, amplia os conhecimentos da criança sobre si mesma e sobre a realidade ao seu redor.

Frequentemente encotramos a padronização das atividades nas escolas e creches, parece ser menos trabalhoso, mas não há uma imbricação social e científica entre as atividades numa sala de aula que justifique o ajuste e administração do tempo de modo 
padronizado e uniforme e, portanto, o rigor no início e término das tarefas cronometricamente. Portanto, a necessidade sem critérios da determinação e sincronização ativa do tempo atende somente a medidas disciplinadoras que desrespeitam o ritmo próprio de cada sujeito.

É preciso deixar que as crianças brinquem, é preciso aprender a rir, a representar, a imitar, a sonhar e a imaginar. $E$, no encontro com elas, incorporando a dimensão humana do brincar, construir o percurso da ampliação e da afirmação de conhecimentos sobre o mundo.

As dimensões de passado, presente e futuro também são distintas entre crianças e adultos. Quanto ao presente, a criança tem a sensação e um sentimento de duração e percepção do tempo, ora mais denso e alongado, ora de tempo fluido, que se dilui e se mistura com o seu eu no ato de brincar. Os adultos não se interrogam e ignoram a percepção subjetiva do tempo da criança, tentando administrar tudo o que ela faz em função de uma objetividade quantificável imposta pelo cronômetro. Como sinônimo de exatidão, disciplina e organização, o Chronos invade as formas mais particulares das crianças se relacionarem com a vida. O caráter instrumental do tempo exerce uma profunda pressão sobre o brincar entre as crianças e talvez nada disso condiga com a natureza e especificidade do brincar, principalmente entre as crianças menores que, por essência, brincam com o tempo.

\section{REFLEXÕES FINAIS: DA ALEGRIA DO BRIN- CAR, A PRESSÂO DOS RELÓGIOS}

Refletir sobre o tempo na educação de crianças é confirmar que a pressa é inimiga da perfeição. O modismo deste jargão não pode, neste momento, ofuscar o que a essência desta afirmação revela. Alguns processos não podem seguir a lógica do culto à velocidade. Cada criança tem seu tempo e tentar não submeter o tempo subjetivo a um tempo homogêneo é uma maneira de encontrar a criança na sua luta pela sobrevivência e de sermos facilitadores para que esta tenha o seu tempo de ser criança respeitado. Os adultos têm atuado como reguladores de suas atividades e isso têm consequências imediatas na experiência social e cultural das crianças e nos diálogos que estabelecem nas suas interações com o mundo, com os outros e consigo mesmo.

Pensa este tempo de ser tempo criança possibilita avançar no sentido de fortalecer a necessidade de aceitar a criança na sua condição de criança e não na expectativa de um ser em potência. Como afirma Comte-sponville (2000): "nãose trata de negar qualquer relação com o futuro, mas se o futuro da criança é ser um adulto, isto é indiferente ao tratamento que deve receber hoje, pois são dois presentes e, por tal, precisam ser ambos entendidos e respeitados".

Concluímos que o aprendizado precoce e a aceleração acadêmica em nada contribuem para o desenvolvimento das crianças. Ao contrário, a ideia de que as crianças devem "aproveitar ao máximo o tempo para obterem bons resultados" podemos destacar que as crianças que são aceleradas e pressionadas desenvolvem "personalidades menos integradas", demonstrando dificuldade de interagir com os outros. A criança tem direito à liberdade de brincar e de se movimentar sem constrangimentos deixando fluir plenamente a imaginação, a fantasia, o prazer, a repetição, a criatividade, a alegria a seu modo, orientada pelas suas formas particulares de lidar com essa linguagem que é original e singular na infância.

Ao que parece o Chronos como referência de um tempo sequencial e matemático fixou-se como um deus moderno reinventado pelos adultos das sociedades industrializadas, enquanto as crianças acreditam em outros deuses que se parecem com Kairos e Aeon. Assim como para Kairos e Aeon o brincar refere-se a um momento indeterminado que nunca tem hora para começar e muito menos para acabar.

Talvez essa tenha sido uma das razões pela qual a mitologia colocou inevitavelmente ao lado de Chronos uma companheira Ananke, pois nem mesmo o Chronos que aprisiona, pressiona e oprime, é por si só independente da própria casualidade de si mesmo e da vida. Assim, cremos plenamente que há uma premência de discutirmos essa questão no interior da atividade humana menos previsível: o brincar das crianças (Costa, 2015).

É preciso reconhecer que as crianças não são absolutamente assujeitadas pelas condições radicais que a segunda modernidade ${ }^{3}$ lhes imputa, haja vista que elas realizam processos de significação e

$3 \quad$ O termo Segunda Modernidade, trazido pelo Professor Manuel Sarmento (2004) caracteriza-se por um conjunto associado e complexo de rupturas sociais, nomeadamente a substituição de uma economia predominantemente industrial por uma economia de serviços, a criação de dispositivos de mercado à escala universal, a deslocalização de empresas, a ruptura do sistema de equilíbrio de terror entre dois blocos, com a crise dos países socialistas do Leste europeu e o fim dos regimes comunistas, a afirmação dos EUA como única potência hegemónica, a conclusão do processo de descolonização dos países africanos, a emergência de uma situação ambiental crítica, as rupturas no mercado de trabalho pela subida das taxas de desemprego, a crise de subsistência dos Estados-Providência, a crescente presença e reclamação na cena internacional de movimentos sociais e protagonistas divergentes das instâncias hegemónicas, a afirmação radical de culturas não ocidentais, nomeadamente de inspiração religiosa, etc. 
estabelecem modos de monitorização das ações que são específicos e genuínos, a exemplo do mundo da fantasia (Sarmento, 2004). No entanto, a nós ainda cabe digerir e compreender como isso arroga efeitos na administração do tempo imposto pelos adultos na direção da criança, entendendo como é ressignificado pela criança e qual seria sua representação numa perspectiva relacional, pois conforme Costa (2015) o brincar da criança também pode ser entendido como um diálogico da criança com o outro, com o mundo e com ela mesmo.

Portanto, refletir sobre a coação do tempo sobre o fenômeno do brincar na Educação Infantil é premente. A escola é uma agência de veiculação dos símbolos sociais e não pode operar com os sentidos que oprimem os saberes e fazeres da criança. A pressão do tempo cronometrado não pode ser naturalizada, funcionando como mero condicionante sócio simbólico indiferente aos desejos e interesses da criança e restringindo a sua liberdade. Para tanto, podemos promover o tempo da liberdade e da espontaneidade para que as crianças dialoguem com sua sensibilidade e intuição livremente e, por consequência, vivenciem a sua humanidade em suas diferentes dimensões e perspectivas.

Não podemos pensar o tempo num paradigma técnico e organizado, mas numa concepção ética e humana baseada no respeito e nos ritmos de cada criança garantindo o crescimento harmônico e equilibrado, levando em conta razão e emoção, e não somente convicções quantitativas, aceleradas e mercantilistas, pois, pela sua natureza, a educação é lenta e necessita de paciência e "tempo".

Por fim, é imprescindível refletir sobre as influencias de um tempo superacelerado em nossa maneira de viver e consequentemente na educação, sobretudo de crianças, que tentamos ao longo deste trabalho discutir, pois, conforme Kunz (2017), o tempo sendo superacelerado, as informações recebidas também o são é justamente na tentativa de não tornar as relações mais frias e instrumentalizadas, que um exame atento sobre o tempo e suas faces necessita ser realizado, sob pena de reproduzir uma educação que distancia as pessoas dos valores que os tornam humanas. Talvez o caminho seja deixar as crianças viver plenamente o seu tempo vital de ser criança, esperar menos delas e, ao invés de oprimi-las deveríamos amá-las e escutá-las mais.

\section{REFERÊNCIAS}

Barbosa M. Por amor e por força: rotinas na educação infantil. Porto Alegre: Artmed; 2006.

Barreto M. Brincadeira de faz-de-conta de crianças em uma turma de Educação Infantil - um estudo Etnográfico em Sociologia da Infância. Braga/Portugal: Universidade do Minho; 2013.

Benjamin W. Reflexões: a criança, o brinquedo, a educação. São Paulo: Summus; 1984.

Borba AN, A; Terra Borba, TNM. Infância, Arte e Educação Infantil: as práticas com as múltiplas linguagens das crianças. In: CRV, editor. Educação Infantil: Arte, cultura e sociedade; 2016. p. 45-62.

Comte-Spomville A. O Ser-Tempo: algumas reflexões sobre o tempo da consciência. São Paulo: Martins Fontes; 2000.

Costa A. Por mais respeito e responsabilidade com crianças: possibilidades de se desenvolver e "brincar e se movimentar" pelo Turnen. Florianópolis - Santa Catarina: Universidade Federal de Santa Catarina; 2015.

Elias N. Sobre o tempo. Rio de Janeiro: Jorge Zahar Editor; 1998.

Fernandes R. O tempo na escola. Porto: Profedições; 2008.

Francesch JD. Elogio de la educación lenta. 3 ed. Barcelona: Editorial Graó; 2011.

Hirsch-Pasek KG, M; Eyer, D. Einstein teve tempo para brincar: como nossos filhos realmente aprendem e porque eles precisam brincar. Rio de Janeiro: Guarda-chuva; 2006.

Honoré C. Devagar. 2 ed. Rio de Janeiro: Record; 2005.

Honoré C. Sob pressão. Rio de Janeiro: Record; 2009.

Kunz E. Brincar e se-movimentar tempos e espaços de vida da criança. 2 ed. Ijuí: Unijuí; 2017.

Bondía J. Notas sobre a experiência e o saber de experiência. Revista Brasileira de Educação. 2002;19:20-8.

Maturana HRV-Z, G.;. Amar e brincar: Fundamentos esquecidos do humano - do patriarcado à democracia. São Paulo: Palas Athena; 2004.

Melucci A. Juventude, tempo e movimentos sociais. São Paulo: Anais da ANPED: Juventude e Contemporaneidade; 1997. p. 125-9.

Sarmento M. As culturas da infância nas encruzilhadas da 2a modernidade. Crianças e miúdos: Perspectivas sociopedagógicas sobre a infância e educação. Vila Nova de Gaia: Edições ASA; 2004. p. 9-34.

Silva A. Jogos, Brinquedos e Brincadeiras: Trajectos Intergeracionais. Portugal: Athaca Editora; 2011. 